\title{
PLATÃo E NIETZSCHE: A TRAMA DRAMÁTICA DA METAFÍSICA
}

\author{
HECTOR BENOIT* \\ Instituto de Filosofia e Ciências Humanas \\ da Universidade de Campinas
}

\begin{abstract}
RESUMO: Neste artigo fazemos algumas reflexões sobre a história interpretativa dos Diálogos de Platão. Particularmente, procuramos mostrar que a crítica de Nietzsche a Platão, que segundo muitos autores aparece como a ruptura definitiva com a metafísica platônico-ocidental, seria apenas mais um momento de continuidade no interior da longa história do platonismo.
\end{abstract}

PALAVRAS-CHAVE: Platão; Nietzsche; platonismo; dialética.

\section{O desconhecimento da léxis}

O pensamento de Nietzsche, segundo representativos autores do pensamento contemporâneo, tais como G. Deleuze, M. Foucault, G. Lebrun, é considerado como o grande articulador da mais devastadora das críticas a Platão e à sua suposta metafísica. Nietzsche, a partir sobretudo da noção de genealogia, teria desvelado as forças negadoras da vida que se escondem sob todas as dialéticas da aparência e da essência, teria aberto o caminho para a libertação de todos os simulacros e assim para a destruição de toda a metafísica platônica ocidental.

No entanto, desde a época do próprio Platão, desde pelo menos o século IV a.C., começaram as primeiras tentativas de fazer a crítica ou destruição da suposta metafísica do autor dos Diálogos. O primeiro grande exemplo nesse sentido foi Aristóteles, com a sua célebre crítica à chamada "teoria das idéias".

Como sabemos, Aristóteles procurou mostrar os diversos paradoxos nos quais mergulham os platônicos quando estabelecem a participação entre as idéias em si e por si (ou autó kath'autó) e as coisas sensíveis. Sabemos a sorte que tiveram na história futura da Filosofia tais paradoxos, sempre enumerados em todos 
os manuais e repetidos em todas as introduções à Filosofia. Toda essa afortunada crítica aristotélica da méthexis ou participação platônica, no entanto, como reconhecem hoje a maioria dos especialistas, é bastante limitada conceitualmente e reduzida em seu valor, devido, sobretudo, à sua relativa falta de originalidade.

Assim como o paradoxo do "terceiro homem", todos os outros argumentos repetidos por Aristóteles até a exaustão, na verdade, estavam já descritos nas próprias páginas do diálogo Parmênides de Platão. Nessas páginas (130 a-e), o jovem Sócrates, já então defensor da "teoria das idéias", assiste toda a sua doutrina ser refutada pelo velho filósofo Parmênides, e exatamente com os mesmos argumentos que, mais tarde, Aristóteles usaria contra a suposta metafísica platônica.

Diante desse texto do próprio Platão, é tão sem originalidade a célebre crítica de Aristóteles que, inconformados com essa estranha coincidência, como se sabe, comentadores do século XIX, como Socher, Ueberweg, Schaarschmidt e outros, levantaram a hipótese de que o diálogo Parmênides seria apócrifo e escrito posteriormente aos textos críticos de Aristóteles. Supuseram estes comentadores que o Parmênides teria sido redigido por algum platônico que teria lido as críticas de Aristóteles e as plagiado. Ora, desde uma comunicação de Lewis Campbell, em 1890, exposta na Sociedade Filológica de Oxford, ficou demonstrada, através da análise estilométrica, a autenticidade irrefutável do Parmênides (Campbell, 1896) ${ }^{1}$, autenticidade esta que jamais voltou a ser contestada.

Se plágio houve, certamente não foi o autor do Parmênides, Platão, que o cometeu. Mas, sugerindo talvez o inverso, ou seja, o plágio da parte de Aristóteles, ironicamente, o sábio autor do Parmênides (Platão), como que prevendo de maneira profética toda esta longa polêmica, colocou entre os personagens que participam do diálogo um jovem que se chama, exatamente, Aristóteles. Teria sido o nome deste personagem uma mera coincidência? Teria sido o nome Aristóteles apenas um mero acaso? Ou então, ao contrário, um dos múltiplos ardis filosóficos que encerram a trama dramática dos Diálogos?

Seja como for, todo esse episódio mostra bem a dificuldade e o risco que correm todos aqueles que pretendem criticar, superar ou mesmo comentar os Diálogos. Sobretudo, agrava-se o risco quando estes críticos ou comentadores não estiverem atentos às articulações da trama dramática, ou, podemos dizer, à trama da léxis, a "ação de dizer" dos Diálogos.

Cito alguns exemplos. O próprio Aristóteles sempre tão pouco atento à léxis, em outra passagem crítica em relação ao platonismo, mais uma vez demonstra a fragilidade da sua leitura. No livro segundo da sua Política, como 
sabemos, Aristóteles critica nos cinco primeiros capítulos as teorias desenvolvidas por Sócrates na República; quando passa no capítulo sexto a comentar as teorias do diálogo Leis, paradoxalmente, Aristóteles continua se referindo a Sócrates (II, 6, 1256 a). Ora, visivelmente, nesta passagem, Aristóteles confunde o personagem chamado de "o Ateniense" com a figura de Sócrates. Como se sabe, Sócrates não é personagem deste diálogo, não é nem sequer citado, e, inclusive, pelos fatos históricos mencionados nas Leis, a cena dramática ocorre já na metade do século IV a.C., ou seja, quase cinqüenta anos após a morte de Sócrates. Seriam identificáveis Sócrates e o Ateniense das Leis? Evidentemente não, como também não são identificáveis os projetos de cidade de ambos.

Mas não acusemos exclusivamente a Aristóteles. Sobretudo, esta questão, a questão "quem fala nos Diálogos?", é uma questão pouco observada por quase toda a longa tradição de leitores que, desde o século IV a.C., começaram a construir a imensa e quase infinita biblioteca de comentadores dos Diálogos.

Para citarmos exemplos contemporâneos, é bem significativo o caso de Victor Goldschmidt; afinal Goldschmidt se celebrizou, particularmente, pelas exigências de rigor e de respeito cuidadoso dos textos. Ora, no seu célebre livro Les Dialogues de Platon, quando Goldschmidt comenta o diálogo Parmênides, se refere à segunda parte dessa obra, como se ainda lá fosse Sócrates o interlocutor que dialoga com Parmênides (Goldschmidt, 1971, p. 150). Ora, como se sabe, após a primeira parte do diálogo, após a demonstração dos paradoxos da teoria das idéias, Sócrates se cala. Sócrates é imobilizado pelas aporias parmenideanas, e assim permanece em silêncio durante toda a segunda parte do diálogo, onde, exatamente, o jovem Aristóteles vem substituí-lo.

Erro similar ocorre em comentário de Louis Méridier. Da mesma forma, confunde Méridier personagens dos Diálogos. Prefaciando o diálogo Crátilo na erudita edição da Belles Lettres, o autor, ao comentar a questão do mobilismo e do imobilismo do Ser, ou seja, a oposição entre heracliteanos e parmenideanos, afirma que somente no diálogo Sofista Sócrates se pronunciará nitidamente contra a concepção de Parmênides ${ }^{2}$. Ora, nos Diálogos de Platão, jamais Sócrates se pronuncia contra a concepção de Parmênides. Na verdade, Méridier confundia nessa passagem Sócrates com o Estrangeiro de Eléia (personagem do Sofista), como se ambos, indistintamente, representassem uma continuidade no pensamento de Platão.

Ora, se lermos com atenção a léxis, a "ação de dizer" dos Diálogos, veremos que Sócrates desde aquele encontro com o velho Parmênides no "tempo de sua bela juventude”, como ele próprio relembra no diálogo Teeteto (183 e - 184 
a), desde aquela época, diz Sócrates, teme enfrentar o sábio eleata. Sócrates jamais romperá com a dialética parmenideana e, sobretudo, sempre permanecerá fiel ao parmenideano interdito do Não-Ser.

Por isso mesmo, para atacar o lógos do pai Parmênides, o pai de todas as dialéticas do Ser, para cometer o histórico "parricídio" do diálogo Sofista, o "parricídio" que dá ser ao Não-Ser, necessariamente, e de maneira precisa, o condutor da demonstração será outro que Sócrates. Para isto aparecerá no diálogo Sofista o personagem conhecido como o Estrangeiro de Eléia. Quem não entende a profunda significação conceitual dessa troca de personagens, quem confunde Sócrates e o Estrangeiro de Eléia, parece-me, pouco compreendeu do próprio conteúdo filosófico dos Diálogos ${ }^{3}$.

No entanto, se muitos helenistas e comentadores contemporâneos ainda interpretam e citam os Diálogos sem levar em conta os personagens, a ação dramática, a materialidade da cena, em uma palavra, a léxis dos Diálogos, se ainda boa parte dos intérpretes contemporâneos ainda lê os Diálogos como se eles fossem um monólogo, como se eles fossem um tradicional tratado filosófico que expressaria de maneira unívoca o lógos, o pensamento ou a doutrina de Platão, todos esses helenistas, intérpretes e comentadores, são apenas bem fiéis à tradição, de longe quase absoluta e hegemônica, uma tradição que se firma desde pelo menos os séculos V e VI d.C.. Refiro-me à tradição cristalizada nos manuais e comentários daquela época, como o manual Prolegômenos à Filosofia de Platão, texto anônimo do século VI, ou como os extensos comentários de Proclus datados do século $\mathrm{V}$.

Nestes textos, em geral muito cuidadosos, em geral muito prolixos, ainda que se perceba e se teorize a respeito da existência dos personagens e, em geral, a respeito da léxis, no entanto, conscientemente, se realiza uma decisiva opção teórica: todos os aspectos da léxis passam a ser considerados apenas como elementos secundários e suboordinados em relação a uma suposta doutrina dogmática de Platão. Para citar apenas um texto, mas que sintetiza bem o problema, lembremos o seguinte trecho do comentário de Proclus à República de Platão. Diz Proclus, na sexta dissertação:

É preciso caracterizar cada autor segundo aquela de suas operações que é a mais nobre e não aquela que é a mais baixa. Pois, caso contrário, poderíamos [incorretamente] considerar Platão um imitador afastado 'em terceiro grau da verdade'. Pois, diz ainda Proclus, há nos diálogos, imitação dos interlocutores bebendo, imitação 
também de personagens em guerra ou em paz, como vimos no Timeu e no Crítias: mas tudo aquilo é acessório, o bem essencial é a doutrina filosófica de Platão (Proclus, p. 199; cf. p. 215).

Ou seja, como explicitará ainda mais adiante Proclus, é absurdo valorizar a parte sensível em Platão, pois este não pode ser confundido com um poeta. Em poetas, como Homero, diz Proclus, realmente a imitação é "a preocupação principal", mas Platão, ao contrário, não pode ser classificado na categoria dos "produtores de simulacros", ou como diz literalmente Proclus, Platão não pode ser classificado "na demiurgia das imagens" (p. 216: te demiourgia ton eidolon).

Como se vê, para a tradição neoplatônica que encerra a Antigüidade e o paganismo, conscientemente, houve uma recusa teórica e quase moral de aceitar a parte, como dizia Proclus, "mais baixa" de Platão. O Platão sensível foi elidido em nome do Platão inteligível. Para Proclus, Platão não podia ele próprio ser confundido com um poeta ou com um sofista, ou ainda, com qualquer demiurgo envolvido nas produções das coisas sensíveis. Platão não podia, ele próprio, ser um imitador afastado em terceiro grau da verdade, Platão não podia, sobretudo, ser classificado como um produtor de simulacros. Ora, com esta decisão hermenêutica do neoplatonismo, enterrava-se definitivamente, para a felicidade dos futuros séculos cristãos, todas as "imoralidades" pagãs da léxis dos Diálogos, e chegava-se ao platonismo hipostasiado, etéreo e purificado, que até hoje predomina, em grande parte, nas nossas interpretações contemporâneas.

\section{Platão e Nietzsche}

Nesse sentido, sem dúvida alguma, a leitura nietzschiana dos Diálogos foi revolucionária. Se a tradição neoplatônica e cristã fez da doutrina do Bem o eixo de todo o seu platonismo moralista, se fez de Sócrates o sacerdote supremo dessa verdade quase revelada, um Sócrates quase santo, muitas vezes, inclusive comparado ao próprio Cristo, ao contrário, através do método genealógico, Nietzsche retornou radicalmente à abandonada léxis dos Diálogos e perguntou, por isso mesmo, de maneira permanente, "quem fala?", "quem fala afinal nos Diálogos de Platão?”. Nietzsche voltava a ler os Diálogos como diálogos, isto é, reconhecendo e observando o processo dialógico.

Nesse movimento, Nietzsche deslocava assim toda a leitura da apreensão de uma sonhada doutrina moral absolutamente pura e sempre em algum sentido 
inacessível, deslocava a leitura dos diálogos para a captação dos desejos e das pulsões dos personagens. Estes desejos e pulsões, mesmo que impuros, imorais e pagãos, foram reintegrados na leitura nietzschiana. Esta leitura nos prometia assim desvelar as verdadeiras forças que agiriam sob as máscaras da procura da verdade, da moral, da justiça.

Nietzsche se detém sobretudo na figura de Sócrates, nas características sensíveis desse personagem: observa que Sócrates era um homem pobre, sem descendência nobre, feio, nariz chato, e observa também que sobretudo entre os belos gregos, as deficiências materiais, sensíveis e estéticas eram sérias objeções. Sócrates era exatamente o contrário daqueles que os gregos admiravam e designavam como kaloi kagathoi, isto é, os belos e bons, Sócrates não era um aristocrata, e sim um plebeu. Mas, Sócrates, como observou ainda Nietzsche, era também um grande erótico ${ }^{4}$ : apesar das suas deficiências, pretendia ser um especialista em ta erotika, isto é, nas coisas do amor; apesar da sua falta de atributos, pretendia seduzir os jovens atenienses. Como poderia realizar, no entanto, os seus objetivos?

Segundo Nietzsche, para se imiscuir entre os belos e nobres atenienses, Sócrates teria desenvolvido, justamente, aquela sua grande e terrível máquina de guerra: a dialética. Com a dialética despotencializava os seus interlocutores, os imobilizava com o seu método de perguntas e respostas, os hipnotizava e afinal os seduzia. Através dos ardis da dialética, através da inversão permanente dos pólos, o sujeito se transforma em objeto, o objeto em sujeito, e ele, Sócrates, pobre, velho e feio, transmutava-se de desejante em desejado, trocava de lugar com os jovens e conseguia ele transformar-se de amante em amado.

Mas, para realizar os seus desejos perversos Sócrates tinha também que inverter todos os principais valores da cultura grega: ao invés da beleza era necessário valorizar a sabedoria e a verdade; ao invés da força física e do poder, era necessário valorizar a moral e a justiça; ao invés do sensível era necessário valorizar o inteligível; ao invés de Dionísio era necessário valorizar Apolo.

A partir dessa sistemática inversão dialética de todos os valores e de todas as polaridades, teria se construído toda a metafísica platônica, um poderoso dispositivo de sedução cujo resultado seria, no entanto, catastrófico. Com a metafísica platônica teria se consagrado a negação doentia e decadente das principais forças da vida (a beleza sensível, a força física, o poder do mais forte). Sendo assim, segundo o nietzschianismo, Sócrates seria o pior de todos os sofistas, aquele que em nome da sua sedução teria criado o terrível veneno da metafísica platõnica. 
Se em relação a Platão, Nietzsche, algumas vezes, mostra até simpatia, é porque, segundo Nietzsche, o jovem poeta trágico Platão teria sido, inclusive, uma das infelizes vítimas da dialética socrática. Se na juventude fora poeta, após a fatal sedução socrática teria rasgado as suas tragédias e passado a seguir cegamente ao velho Sócrates, o poeta se transformou então em filósofo e escreveu os Diálogos.

Como se sabe, todos estes temas da leitura nietzschiana dos Diálogos, desde o Nascimento da Tragédia, estão espalhados nas diversas obras de Nietzsche e são os fundamentos da sua crítica à metafísica 5 .

Sem dúvida, como já dissemos, toda essa temática da leitura nietzschiana teve o grande mérito de romper com a tradição neoplatônica e cristã que havia renunciado totalmente a observar a léxis dos Diálogos. Nietzsche, na sua crítica, recolocou a ênfase na léxis, na "ação de dizer", e permitiu que voltássemos a ler os Diálogos como diálogos, diálogos entre diversos personagens que realmente são repletos de desejos e atos pagãos, ou se quisermos, para usarmos as expressões de Proclus, "desejos e atos vis", "atos afastados em terceiro grau da verdade".

Se este é realmente um mérito inquestionável da leitura nietzschiana, até que ponto, no entanto, podemos encontrar méritos reais nos resultados dessa leitura, sobretudo, enquanto uma suposta crítica ou destruição definitiva da metafísica platônica ${ }^{6}$ ? A leitura nietzschiana teria realmente através dos seus procedimentos genealógicos de fato realizado a superação ou renversement do platonismo (para usarmos uma expressão de Deleuze)? Ou, ao contrário, Nietzsche, como já Aristóteles no século IV a. C., não teria sido ele também mais um pretensioso, inocente e não original crítico dos Diálogos? Isto é, assim como a crítica aristotélica à teoria das idéias (antecipada no diálogo Parmênides pelo próprio Platão), a crítica nietzschiana à metafísica platônica não seria apenas mais uma crítica ao autor dos Diálogos que, na verdade, inocentemente, parte do interior dos próprios Diálogos? Nesse sentido, justamente, gostaria aqui de fazer algumas observações.

\section{Limites da crítica nietzschiana}

Realmente se observarmos com atenção os diversos temas da crítica nietzschiana acima enumerados, veremos que eles aparecem como originais e até surpreendentes, mas, somente para aqueles leitores que estão habituados com a 
leitura da tradição. Ao contrário, se nos voltarmos justamente para os próprios Diálogos e os lermos enquanto diálogos, desde o início, respeitando a sua léxis, respeitando a existência de personagens e de toda uma série de indícios sensíveis que compõem a cena dramática, veremos que a leitura de Nietzsche não somente não é surpreendente ou original, como, podemos até dizer, ao contrário, é até redundante e inocente. Vejamos os diversos temas da crítica nietzschiana.

Em primeiro lugar, a questão "quem fala?". Seria isto algo original diante dos Diálogos? Evidentemente não. Em diversos diálogos aparece a discussão e a explicitação da importância dessa questão. Por exemplo, no diálogo Alcibíades I, a uma certa altura da discussão, Sócrates se detém neste tema e longamente argumenta a respeito de quem fala quando alguém interroga e quando alguém responde. Assim em 113-a, chega a perguntar Sócrates: "Se eu te perguntasse como se escreve o nome de Sócrates e tu o dissesses, qual de nós dois é o que está dizendo (poteros ho legon)?". E logo depois ainda acrescenta Sócrates: "quando há troca de questões e de respostas, qual é aquele que diz as coisas? É aquele que questiona ou aquele que responde?". Assim aqui é o próprio Sócrates que, teorizando a respeito da forma diálogo, coloca a questão quem fala?

Se muitas passagens como essas poderiam ser citadas onde se teoriza a forma diálogo, evidentemente, não foi sem muito meditar filosoficamente a respeito de quem fala que o próprio Platão utilizou essa forma, a forma dialógica. Este é um tema fundamental da própria estrutura da sua obra, inclusive, sempre precisamente pensado na introdução de cada personagem, na mutação dos condutores e interlocutores nas diversas passagens dos Diálogos, na sobreposição de estruturas narrativas, e finalmente, na ausência significativa dele próprio, Platão, autor jamais plenamente soberano, autor que, apesar de citado três vezes, jamais toma a palavra ele próprio em sua própria obra.

Ainda que talvez apócrifas, são significativas neste sentido as palavras que se lêem na Carta II atribuída a Platão: "não existe obra de Platão e não existirá" (314 c). Na mesma direção podemos lembrar as palavras que lhe são atribuídas no manual anônimo do século VI, Prolegômenos. Segundo o anônimo, teria dito Platão: "não sei nada, não ensino nada, apenas percorro aporias" (p. 17: ouden oida oute didasko ti, alla diaporo monon).

Existe a doutrina de Platão? Onde está Platão nos Diálogos? Quem fala afinal nos Diálogos de Platão? A pergunta não somente foi colocada pelos próprios Diálogos, como também, a resposta a quem fala nos Diálogos, parece-me, é bem mais complexa do que sempre pensaram a tradição e também Nietzsche. 
Sem que aqui possamos nos estender neste tema, basta lembrar que a tradição (ao menos aquela posterior à Media e à Nova Academia ${ }^{7}$ ) sempre pensou que o pensamento de Platão é aquele expresso por Sócrates nos Diálogos e atribui ao "pensamento de Platão" tudo o que diz Sócrates.

Se Nietzsche diferenciou Sócrates e Platão, os diferenciou apenas como personagens sensíveis, mas não na instância do pensamento. Para Nietzsche, Platão teria sido seduzido por Sócrates e finalmente teria produzido a chamada "metafísica platônica", ora, para Nietzsche, nesta metafísica falam as mesmas forças que se manifestam no ressentimento socrático, as mesmas forças negadoras da vida. Nem a tradição nem Nietzsche perceberam a distância claramente demarcada nos Diálogos entre o que expressa o personagem Sócrates e um possível conteúdo absoluto dos Diálogos.

Aquilo que diz o personagem Sócrates está longe de coincidir com um suposto pensamento ou doutrina absoluta de Platão. Isto fica claro sobretudo se lermos com atenção o Parmênides, o Politico, o Sofista e as Leis (diálogos onde Sócrates deixa de ser o condutor). Mas, sem dúvida, está indicado também no Banquete e em muitos outros diálogos, onde a figura de Sócrates aparece como fundamental.

Sendo assim a pergunta quem fala? não somente não é um tema original do nietzschianismo, como também, me parece, a sua resposta (a resposta nietzschiana) é bastante inocente quando nem sequer percebe a profunda complexidade dos personagens dos Diálogos.

Ora, não muito diferente ocorre em relação aos outros temas da crítica nietzschiana. $\mathrm{Na}$ verdade, eles são todos extraídos dos próprios Diálogos. O tema por exemplo da feiura física de Sócrates é tratado em diversos diálogos (entre outros lembremos o Banquete e o Teeteto). O tema de que Sócrates apesar de feio fisicamente se pretendia um sedutor é amplamente tematizado também em diversos diálogos: Lysis, Cármides, Alcibíades I, Banquete, e mesmo no Fedro. A denúncia do caráter sedutor-hipnotizador da dialética socrática também não é um tema original de Nietzsche, como se sabe; a isso se referem diversos personagens, particularmente Menon, que chega a compará-lo à tremelga do mar, peixe que imobiliza a quem dele se aproxima.

A própria acusação de que Sócrates trocava de lugar com o seu seduzido, que o velho Sócrates se transformava assim em amado, e o jovem belo se transformava em amante, mesmo essa acusação aparentemente tão vil e tão cara ao nietzschianismo (Rey, 1971, p. 99-100), nem mesmo ela, como se sabe, é original; basta lermos o discurso de Alcibíades no Banquete, onde este justamente adverte a 
Agatão e aos outros que Sócrates sempre fazia isso, transformando-se de amante em amado ${ }^{8}$.

Como se vê, os diversos temas da crítica nietzschiana alardeados como a destruição da metafísica platônica, como a ação devastadora do genealogista que com seu novo método descobriria as forças escondidas sob a vontade mais secreta de Sócrates, na verdade, para quem lê com atenção os velhos Diálogos, todos esses temas são repetições nada originais de temas desenvolvidos nos próprios Diálogos.

Até mesmo aquele tema tão explorado pelo nietzschianismo de que Sócrates seria talvez o mais sedutor de todos os sofistas, nem mesmo este tema pode-se considerar original após uma leitura atenta do diálogo Sofista. Como se sabe, nas diversas definições que o Estrangeiro de Eléia produz a respeito do "ser" do sofista, Sócrates escapa somente nas últimas divisões, e particularmente a última definição serve para Sócrates mas não, surpreendentemente, para Górgias, Polos, Trasímaco ou outros conhecidos sofistas. Como afirma o Estrangeiro de Eléia ao final do diálogo, o sofista "pratica a sua arte em reuniões privadas, corta seus discursos em argumentos breves e obriga o seu interlocutor a se contradizer a si próprio" (268b). Ora, os sofistas se caracterizavam justamente por amar os longos discursos e não os argumentos breves; assim como também o método de levar o seu interlocutor à contradição, o método refutativo, caracterizava a Sócrates, mas não aos sofistas.

Diante disso, o que restou de verdadeiramente original e inovador na crítica nietzschiana aos Diálogos? Todos os seus temas, desde a questão quem fala? até a acusação de que Sócrates seria o mais sedutor de todos os sofistas, são temas extraídos dos próprios Diálogos. Como pretender destruir a suposta metafísica platônica a partir dos próprios Diálogos? Como a crítica de Aristóteles à teoria das idéias e como tantas outras críticas ao platonismo, parece-me que também a crítica nietzschiana, apesar do seu grande alarde, será um dia reconhecida como apenas mais uma das múltiplas figuras que, desde sempre, estiveram presentes já, lá, nas velhas páginas dos Diálogos.

Mas, entenda-se bem, reconhecer isto significa apenas reconhecer que como o aristotelismo (com a sua metafísica do universal porque primeiro, ou do ser que não é gênero), como o hegelianismo (com a sua retomada das reflexões sobre o não-ser e da dialética inspiradas, sem dúvida, nas páginas do diálogo Sofista), assim também o nietzschianismo (com a sua retomada da léxis dos Diálogos de Platão e de todo o paganismo dos seus personagens, com o seu projeto da libertação de todos os simulacros), assim também o nietzschianismo é fundamen- 
tal figura para compreender ao próprio Platão e ao platonismo, no entanto, ainda a partir dele e através dele.

\section{Notas}

* Professor Doutor do Departamento de Filosofia do IFCH da UNICAMP e Professor Visitante do Programa de Pós-Graduação em Letras Clássicas da FFLCH-USP.

1 Todo o histórico da questão é exposto por Diés (Diés, 1965, p. IX-XI).

2 C'est seulement dansle Sophiste qu'il[ [Sócrates] se prononcera nettement contre la conception de Parménide. Toutefois Socrate déclare... (Méridier, 1931, p. 32).

3 No diálogo Sofista abandona-se a dialética de tipo parmenideano (ou seja, dialética do ser), e passa-se para uma nova forma de dialética, aquela que admite a contradição e o não-ser.

4 Sokrates war auch ein grosser Erotiker (Nietzsche, 1930, p. 91).

5 Se quisermos privilegiar no entanto um texto em particular, devemos lembrar, sem dúvida, os doze aforismos de $O$ Crepúsculo dos Ídolos, que Nietzsche denomina "O problema Sócrates" (Nietzche, 1930).

6 Sobre a pretensa crítica nietzschiana à metafísica platônica, para citarmos somente um texto, podemos lembrar os seis aforismos de Crepúsculo dos Ídolos, intitulados "Como o 'verdadeiro mundo' finalmente se tornou uma fábula", que possuem ainda o subtítulo "História de um erro". Pretende-se narrar uma pequena história da metafísica. Começa com a frase: ich, Plato, bin die Wahrheit "eu, Platão, sou a verdade", passa pelo momento do cristianismo e por outros momentos, tais como o kantiano, até que já no quinto estágio "Platão ruboriza de vergonha" (Schamröte Platos), e a noção de um mundo verdadeiro oposto a um mundo aparente começa a desaparecer. Finalmente, no sexto momento, é o fim da história desse erro, superam-se o mundo verdadeiro e também o aparente, é o meio-dia, a hora de Zaratustra (Nietzsche, 1930, p. 99-100).

7 Arcesilau, Carneades, Filon de Larissa foram alguns dos platônicos não-dogmáticos, chegando a se confundir com o ceticismo, como se pode conferir nos comentários de Sextus Empiricus.

8 Também no final do Alcibíades Iocorre a inversão.

\section{REFERÊNCIAS BibLIOGRÁficAS}

CAMPBELL, L. On the place of Parmenides. Classical review. Oxford, v. X, p.12936, April-1896. 
DIÉS, A. Notice générale du Parménide. In: PLATON. Parménide. Paris: Les Belles Lettres, 1965.

GOLDSCHMIDT, V. Les Dialogues de Platon. 3 ed. Paris: PUF, 1971.

MÉRIDIER, L. Notice générale du Cratyle. In: PLATON. Cratyle. Paris: Les Belles Lettres, 1931.

Prolégomènes à la philosophie de Platon. Texte établi par L. G. Westerink et traduit par J. Trouillard. Paris: Les Belles Lettres, 1990.

PROCLUS. Commentaire sur la République. Traduction e notes par A. J. Festugière. Paris: Vrin / C.N.R.S.. t. 1.

NIETZSCHE, F. Das Problem des Sokrates. In: - . Werke: Götzen-Dämmerung. Leipzig: A. Kröner, 1930. v. 5, p. 87-93.

REY, J.-M. L'Enjeu des Signes. Lecture de Nietzsche. Paris: Seuil, 1971.

BENOIT, Alcides Héctor Rodriguez. Platon et Nietzsche.

RÉSUMÉ: Dans cet article on trouve quelques reflexions sur l'histoire interpretative des Dialogues de Platon. Particulièrement, on cherche à demontrer que la critique de Nietzsche à Platon, laquelle, selon beaucoup d'auteurs, apparait comme la rupture definitive avec la métaphysique platonicienne-occidentale, n'est qu'un moment en plus de continuité dans la longue histoire du platonisme.

MOTS-CLÉS: Platon; Nietzsche; platonisme; dialectique. 